\title{
ASSESMENT OF THE INFLUENCE OF UAV IMAGE QUALITY ON THE ORTHOPHOTO PRODUCTION
}

\author{
D. Wierzbicki ${ }^{\text {a*}}$, M. Kedzierski ${ }^{a}$, A. Fryskowska ${ }^{a}$ \\ ${ }^{a}$ Department of Remote Sensing and Photogrammetry, Institute of Geodesy, Faculty of Civil Engineering and Geodesy, Military \\ University of Technology, 2 gen. Sylwestra Kaliskiego st., 00-908 Warsaw, Poland \\ (dwierzbicki, mkedzierski, afryskowska@wat.edu.pl)
}

\section{Commission ICWG I/Vb}

KEY WORDS: Photogrammetry, Unmanned Aerial Vehicle, Bundle Block Adjustment, Image Quality, Point Cloud

\begin{abstract}
:
Over the past years a noticeable increase of interest in using Unmanned Aerial Vehicles (UAV) for acquiring low altitude images has been observed. This method creates new possibilities of using geodata captured from low altitudes to generate large scale orthophotos. Because of comparatively low costs, UAV aerial surveying systems find many applications in photogrammetry and remote sensing. One of the most significant problems with automation of processing of image data acquired with this method is its low accuracy. This paper presents the following stages of acquisition and processing of images collected in various weather and lighting conditions: aerotriangulation, generating of Digital Terrain Models (DTMs), orthorectification and mosaicking. In the research a compact, non-metric camera, mounted on a fuselage powered by an electric motor was used. The tested area covered flat, agricultural and woodland terrains. Aerotriangulation and point cloud accuracy as well as generated digital terrain model and mosaic exactness were examined. Dense multiple image matching was used as a benchmark. The processing and analysis were carried out with INPHO UASMaster programme. Based on performed accuracy analysis it was stated that images acquired in poor weather conditions (cloudy, precipitation) degrade the final quality and accuracy of a photogrammetric product by an average of $25 \%$.
\end{abstract}

\section{INTRODUCTION}

Numerous researches into using images acquired by Unmanned Aerial Vehicles (UAV) have been leading to the continuous development of this technique for photogrammetric projects. Due to lower, compared to traditional photogrammetry costs, it is becoming more and more popular in many engineering applications. Unfortunately, using non-metric digital cameras of low radiometric accuracy for this technique results in significant problems with the image processing automation. At the data acquisition stage, the camera exposition parameters (shutter speed, aperture value) and weather conditions have a considerable impact on the final image quality. Other factors determining geometric accuracy are the motion blur and image inclination angle effects. The latter are mainly caused by the vehicle flight stability, which can possibly be disturbed by the engine vibrations, turbulences and sudden wind flows. The UAV data acquisition and processing methods constitute a wide research field in terms of creating new solutions and improving the existing solutions of the photogrammetric products' accuracy (Hermandez-Lopez et al., 2013; Mancini et al., 2013). Yet hitherto, apart from the above-mentioned aspects of data collection from low altitudes in different weather conditions, the final image quality's impact on the accuracy of photogrammetric products has not been considered.

Lately, significant progress in the development of image matching algorithms has been observed. Until now, the methods most commonly used were traditional image matching methods, based on area matching (ABM) or feature based matching (FBM) (Förstner, Gülch, 1987; Grün, 1985; Schenk, 1999). The newly developed methods are based on each single image pixel matching (image dense matching). Developing the semi-global matching algorithm by Hirschmüller (Hirschmüller, 2005, 2011) is believed to be a milestone in the field of image matching. Over the past few years, this and other similar algorithms have been extensively studied for applications in photogrammetry (Cavegn, et al., 2014; Haala, 2014; Rupnik, et al., 2014; Haala, 2011; Rothermel, Haala, 2011; Gerke, 2009; Tasai, Fan, 2007).

The paper compares the results of the blocks alignment and point cloud generation, as well as the results of generating orthomosaics using image data acquired in different weather conditions.

The following section presents the UAV-platform and the camera used in the research. Section 3 discusses the flight campaigns in different weather conditions. Section 4 describes bundle block adjustment and results. Section 5 refers to dense point extraction and compares its products. In section 6 the DTM extraction was presented. Section 7 describes orthorectification and mosaicking processes. A discussion was undertaken and concluded in the last section of this paper.

\section{UAV PLATFORM AND CAMERA}

The low altitude image data was acquired by a UX5 platform, which can be classified as a mini-sized UAV (Fig. 1.)

\footnotetext{
* Corresponding author - Damian Wierzbicki, dwierzbicki@ wat.edu.pl, +48 226839692
} 


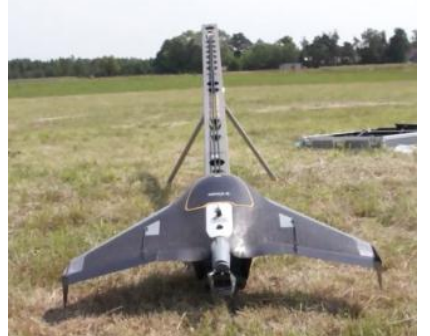

Figure 1. Trimble UX-5 - before flight

The airframe allows fully autonomous flight at the desired height at a preset side-lap and over-lap images coverage. The system includes a flight controller enabling real time flight parameters management. Table 1 shows the basic specifications of the platform.

\begin{tabular}{|c|c|}
\hline Type & Body with the wings \\
\hline Weight & $2,5 \mathrm{~kg}$ \\
\hline Wing span & $1 \mathrm{~m}$ \\
\hline Wing surface & $34 \mathrm{dm} 2$ \\
\hline Dimensions & $100 \times 65 \times 10 \mathrm{~cm}$ \\
\hline Motor & $\begin{array}{c}\text { Electric motor with propellers } \\
\text { (motor power } 700 \mathrm{~W} \text { ) }\end{array}$ \\
\hline Battery & $14.8 \mathrm{~V}, 6000 \mathrm{mAh}$ \\
\hline
\end{tabular}

Table 1. Technical parameters Trimble UX5

UX5 lets the user control the automatic takeoff, flight and landing. Images are taken using an automatic camera shutter release. Safety of flights is controlled automatically, however, it is possible for the operator to intervene by controlling the emergency safety procedures. The takeoff is possible from the mechanical launcher only.

The system is operable for wind speed not exceeding $18 \mathrm{~m} / \mathrm{s}$ and in weather conditions no worse than a light rain. The images can be captured from an altitude ranging from 75 to $750 \mathrm{~m}$ with ground resolution from 2.4 to $24 \mathrm{~cm}$. The image data was obtained by Sony NEX-5R digital camera, which is one of the most commonly selected sensors mounted on board unmanned aerial vehicles. Captured images are saved in JPEG format. For Trimble UX5 platform pictures are taken with a super bright Voigtlander lens with $15 \mathrm{~mm}$ focal length and the maximum aperture equal $\mathrm{F} 4.5$.

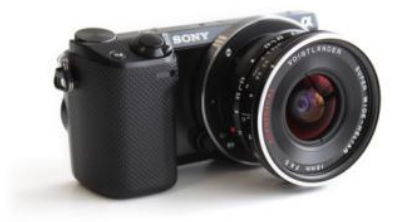

Figure 2. Sony NEX5R digital camera with Voigtlander $15 \mathrm{~mm}$ lens

\section{FLIGHT CAMPAIGNS}

The light campaigns were performed in two separate periods, with dissimilar lighting and weather conditions and at different altitudes. All acquired digital images were saved in JPEG lossy compression format with radiometric resolution of 8 bits per channel. Weather and lighting conditions were characterised by the following criteria:
- Good weather - cloudless sky or small clouds. The average light intensity 11000 lux,

- Poor weather - overcast, the occurrence of fog or rain. The average light intensity 1000 lux.

\subsection{Test Area}

For our tests we chose the region of Chrzesne village, located $40 \mathrm{~km}$ north-east of Warsaw (Poland). The imaged area covered $4.4 \mathrm{~km}^{2}$ of flat, partially wooded terrain with single standalone buildings. Image data from the low altitude was obtained in two flight campaigns, in different lighting and weather conditions. On the test field 16 signalised control points were designed and measured with GPS RTK technique with $3 \mathrm{~cm}$ accuracy. Figure 2. shows the Ground Control Point signal.
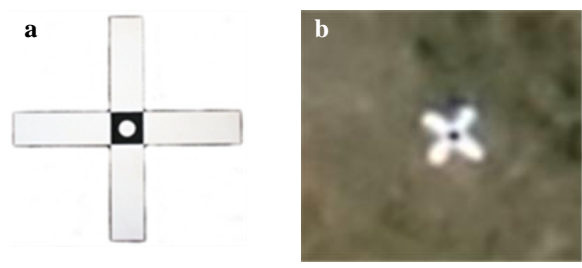

Figure 2. Ground Control Point signals: a) Designed GCP

b) Photographed GCP

\subsection{The first campaign - poor weather}

The flight was performed in August, 2014 at 10:00 - 11:00 local time over a $1250 \mathrm{~m}$ x $3750 \mathrm{~m}$ wide area. The weather condition for photographing was unfavourable; during the first flight the sky was strongly overcast, with additional fog and light rain. The sun was about $42^{\circ}$ high above the horizon and the wind speed was equal to approximately $3.9 \mathrm{~m} / \mathrm{s}$. Trimble UX5 airframe with a SONY NEX5R camera were used to obtain the data. The flight was planned in the Trimble Aerial Imaging software. Camera preferences were defined manually and the lens focus was set to infinity. The ISO sensitivity was set to AUTO and the aperture was set to 4.5. Due to very poor lighting conditions, shutter speed had to be set as high as possible, and was fixed at $1 / 2500 \mathrm{~s}$. In this test, a great number of images were visibly blurred, which further degraded the image radiometric quality. During the first flight 980 images were taken at the altitude of $200 \mathrm{~m}$, with ground pixel size equal to $0.06 \mathrm{~m}$. Forward and side overlap was equal to $75 \%$. The raids were performed in the East-West direction.

\subsection{The second campaign - good weather}

The flight was performed in September, 2014 at 11:00 - 12:00 local time over a $1200 \mathrm{~m} \times 3700 \mathrm{~m}$ wide area. The weather conditions for photographing were favourable. The sun was about $35^{\circ}$ high above the horizon and the wind speed was equal to approximately $2.7 \mathrm{~m} / \mathrm{s}$. The same airframe and camera system were used to obtain the data. The ISO sensitivity was set to AUTO and the aperture was fixed at 4.5. With good lighting conditions the exposure time was set as $1 / 2000 \mathrm{~s}$. During the campaign 1184 images were taken at an altitude of $200 \mathrm{~m}$, with ground pixel size equal to $0.06 \mathrm{~m}$. Forward and side overlap was $75 \%$. The raids were performed in the East-West direction. 


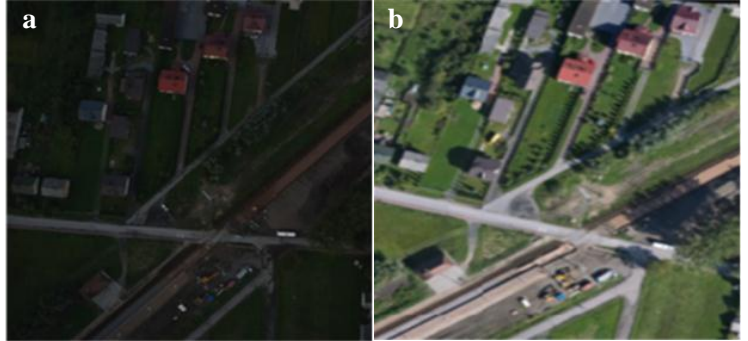

Figure 3. The same area imaged under a) cloudy sky and fog

b) under a clear sky and good sunlight

\section{BUNDLE BLOCK ADJUSTMENT}

In case of image data collection from low altitudes, the Automatic digital Aerial Triangulation (AAT) is still the most important step in the relative and absolute orientation of images' block. The problem of the imaging platform instability and non-metric digital camera usage present in acquiring images from low altitudes worsens the geometry of images (relatively large values of the forward and sidelap inclination angles), compared to traditional digital aerial photographs (Hardin, Jensen, 2011). Therefore, low ceiling image data is usually characterised by high values of forward and side overlap (above $70-80 \%$ ). The low accuracy of the GPS-INS sensors is another factor imposing high overlap requirement. Currently, on board unmanned aerial vehicles the sensors most commonly installed are single frequency GPS receivers, which determine the position with accuracy not higher than single meters.

In relation to determining values of the angular camera orientation parameters, inertial sensors based on Micro ElectroMechanical Systems, MEMS are the most frequent choice of the low cost UAVs designers (Kędzierski, et al., 2013). The achievable accuracy of determining the angular values for such type of sensors reaches up to $1^{\circ}$ for angles of the forward and side overlap, and up to $2^{\circ}$ for the rotation angle (Chao et al., 2010). Low accuracies of angle parameter estimations are caused mainly by accelerometric- gyroscopic measurements' errors as well as by inaccurate magnetometer reads.

Thanks to the intensive development of multiple Computer Vision techniques, photogrammetric systems designed for low altitude image data processing have been extensively enhanced. This may include the following software: INPHO UasMaster, Trimble Business Center Photogrammetry, AgiSoft Photoscan, Pix4D, EnsoMosaic etc. These systems automatically generate large numbers of tie points, based on Structure from Motion algorithms (Westboy, et al., 2012), using the SGM algorithm (Hirschmuller, 2005) and SIFT operator (Lowe, 2004). However, in order to increase the reliability of our results for the auto-calibration final alignment, the only included tie point were those occurring on at least three images. The photogrammetric blocks were bundle adjusted in INPHO UASMaster and MATCH-AT software.

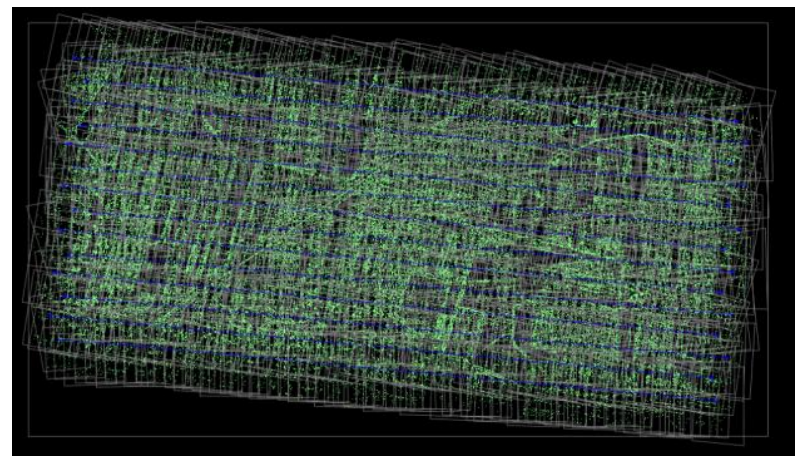

Figure 4. Image block with automatic tie points - UASMaster

In the process of triangulating a block of aerial photographs, the adjustment's accuracy is measured by the sigma naught $\sigma_{0}$ error value. However, in our experiment, the most attention was paid to values of standard deviations which had been computed for all the tie points included in the bundle adjustment. The standard deviations mentioned above estimate the accuracy of determining coordinates of any tie point in the aerial triangulation network. Therefore, each tie point measured in such a network will be statistically determined with a precision equal to the average standard deviation. In the presented analysis 16 points were introduced as the control points, while the remaining 5 were used as check points. Tie points measurements were generated by the Cost Based Matching option, available within the UASMaster. Table 2 presents the results of bundle adjusting two blocks consisting of images obtained in different weather conditions. 


\begin{tabular}{|c|c|c|c|}
\hline \multirow{2}{*}{\multicolumn{2}{|c|}{$\begin{array}{c}\text { Description } \\
\text { Weather } \\
\text { conditions }\end{array}$}} & \multicolumn{2}{|c|}{ Images blocks } \\
\hline & & $\begin{array}{c}\text { Poor } \\
\text { (overcast, } \\
\text { fog) }\end{array}$ & $\begin{array}{c}\text { Good } \\
\text { (cloudless, } \\
\text { sunny) }\end{array}$ \\
\hline \multicolumn{2}{|c|}{ Number of photos } & 980 & 1184 \\
\hline \multicolumn{2}{|c|}{$\sigma_{0}[\mu \mathrm{m}] /[\mathrm{pix}]$} & $7.4 / 1.5$ & $5.4 / 1.1$ \\
\hline \multicolumn{2}{|c|}{ Number of GCPs } & \multicolumn{2}{|c|}{16} \\
\hline \multicolumn{2}{|c|}{$\begin{array}{c}\text { Number of tie } \\
\text { points }\end{array}$} & \multicolumn{2}{|c|}{5} \\
\hline \multirow{3}{*}{$\begin{array}{c}\text { Average } \\
\text { a'priori error } \\
\text { for GCPs and } \\
\text { tie points } \\
\mathrm{X}, \mathrm{Y}, \mathrm{Z},[\mathrm{m}]\end{array}$} & $\mathbf{X}$ & \multicolumn{2}{|c|}{0,03} \\
\hline & $\mathbf{Y}$ & \multicolumn{2}{|c|}{0,03} \\
\hline & $\mathbf{Z}$ & \multicolumn{2}{|c|}{0,03} \\
\hline \multirow{3}{*}{$\begin{array}{c}\text { Standard } \\
\text { deviation for } \\
\mathrm{X}, \mathrm{Y}, \mathrm{Z}[\mathrm{m}] \\
\text { coordinates' } \\
\text { components }\end{array}$} & $\mathbf{X}$ & 0.05 & 0.05 \\
\hline & $\mathbf{Y}$ & 0.08 & 0.04 \\
\hline & $\mathbf{Z}$ & 0.19 & 0.11 \\
\hline \multirow{3}{*}{$\begin{array}{l}\text { GCPs } \\
\text { X, Y, Z [m] } \\
\quad \text { RMS }\end{array}$} & $\mathbf{X}$ & 0.06 & 0.03 \\
\hline & $\mathbf{Y}$ & 0.08 & 0.04 \\
\hline & $\mathbf{Z}$ & 0.13 & 0.06 \\
\hline \multirow{3}{*}{$\begin{array}{l}\text { Tie points } \\
\text { X, Y, Z [m] } \\
\quad \text { RMS }\end{array}$} & $\mathbf{X}$ & 0.08 & 0.04 \\
\hline & $\mathbf{Y}$ & 0.09 & 0.06 \\
\hline & $\mathbf{Z}$ & 0.14 & 0.10 \\
\hline \multicolumn{2}{|l|}{$\mathbf{M X}_{0}[\mathrm{~m}]$} & 0.16 & 0.13 \\
\hline \multicolumn{2}{|l|}{$\mathbf{M Y}_{0}[\mathrm{~m}]$} & 0.12 & 0.10 \\
\hline \multicolumn{2}{|l|}{$\mathbf{M Z}_{0}[\mathrm{~m}]$} & 0.23 & 0.12 \\
\hline \multicolumn{2}{|l|}{$\mathbf{M} \omega\left[^{\circ}\right]$} & 0.038 & 0.022 \\
\hline \multicolumn{2}{|l|}{ М $\left[^{\circ}\right]$} & 0.047 & 0.025 \\
\hline \multicolumn{2}{|l|}{ Мк $\left[{ }^{\circ}\right]$} & 0.015 & 0.007 \\
\hline
\end{tabular}

Table 2. Bundle Block Adjustment - results

Based on the above presented results' analysis it can be concluded that the quality of images obtained in poor weather conditions noticeably affects the adjustment results, compared to the outcomes obtained with images taken in good weather conditions. For the first test block sigma naught was as high as 7.4 microns (1.5 pixels), while for the second block, this value was about 2 microns smaller. Analysing the $\mathrm{X}, \mathrm{Y}, \mathrm{Z}$ coordinates' standard deviations may give an impression that the adjustment in both cases gave satisfactory results. However the further investigations of joint lines numbers on the tie points shows that in case of the first block there were noticeably less tie points generated, while the joint lines between the images was also poor (high number of tie points measured on two images only). It can be concluded that the mentioned correlation algorithm is not powerful enough for images of poor radiometric quality. For the first block, the Ground Control Point RMSE values fall within $0.05-0.19 \mathrm{~m}$, while the second block (good weather) RMSE values were found to lie between $0.04-0.11 \mathrm{~m}$. The check points RMS values fall within $0.08-$ 0.14 and $0.04-0.10 \mathrm{~m}$ for the poor and good weather conditions blocks respectively. The first block adjustment gave satisfactory results in perspective centre $\mathrm{X}_{0}, \mathrm{Y}_{0}, \mathrm{Z}_{0}$ coordinates' estimation. Standard deviations for the first block fell within $0.12-0.23 \mathrm{~m}$, while the second block values lied between $0.10-0.13 \mathrm{~m}$. The accuracy of estimating the exterior orientation angular parameters $\omega, \varphi$ and $\kappa$ for the first block fell within $0.015^{0}$ to $0.047^{0}$, while for the second block the results were almost twice as good and ranged from $0.007^{\circ}$ to $0.025^{\circ}$. Based on the results in Table 2, it can be stated that the adjustment gave satisfactory results. This is confirmed by the standard deviations of $\mathrm{X}, \mathrm{Y}$ coordinates being close to a'priori error values. Due to the terrain type, these values were twice as high for the $\mathrm{Z}$ coordinate. Based on analysis of erroneous observations it can be concluded that the lack of tie points on images taken in the poor weather conditions was caused by lower radiometric quality, compared to the images acquired in good weather conditions. Investigation of the two blocks has shown that on the block composed of images acquired in good weather conditions there were $20 \%$ more tie points created in the Gruber zone, compared to the first block.

\section{DENSE POINT CLOUD EXTRACTION}

The DSM generating algorithms based on digital image correlation have been known for more than two decades (Förstner, 1995; Haala, 2009; Gülch, 2009; Haala et al., 2010). However, the semi-global matching algorithm developed by Hirschmüller (Hirschmüller, 2005) revolutionised this sector recently. A high performance level with high success ratios, good penetration in $3 \mathrm{D}$ objects and high accuracy are obtained by using large image overlaps and matching multiple images in each single point (Rosnell, Honkavaara, 2012). The point clouds were generated from UAV images in UASMaster programme.

The methodology for assessing the quality of the point cloud was based on comparing two relative clouds. Comparison of the distance between point clouds allows to estimate direction or any deformation. In order to evaluate the absolute point cloud geometry, the Ground Control Points and Independent Check Points not included in dense matching process were used. Comparing coordinates measured on a point cloud with the coordinates of GPS RTK allows for determination of the absolute values of the generated point clouds geometry errors. In addition, visual analysis were performed, on the basis of which we identified shortcomings and errors in the point cloud generated using images acquired in poor weather conditions, compared to the point cloud obtained from images acquired in good weather. We analysed such objects as forests and buildings. Table 3 presents the statistics for the two point clouds.

\begin{tabular}{|c|c|c|}
\hline & $\begin{array}{c}\text { Point Cloud I } \\
\text { (poor weather } \\
\text { conditions) }\end{array}$ & $\begin{array}{c}\text { Point Cloud II } \\
\text { (good weather } \\
\text { conditions) }\end{array}$ \\
\hline $\begin{array}{c}\text { Number of points } \\
\text { generated }\end{array}$ & 26541980 & 34446700 \\
\hline $\begin{array}{c}\text { Average point } \\
\text { spacing (m) }\end{array}$ & 0.41 & 0.37 \\
\hline $\begin{array}{c}\text { Point Density } \\
\text { (points } / \mathrm{m}^{2} \text { ) }\end{array}$ & 7 & 8 \\
\hline
\end{tabular}

Table 3. Statistics for generated PCs 


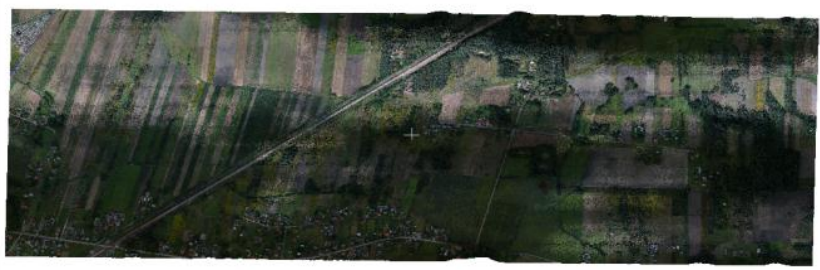

Figure 5. Point Cloud generated from low quality images (poor weather condition)

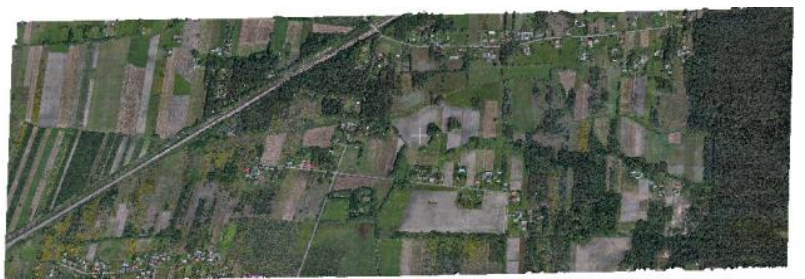

Figure 6. Point Cloud generated from high quality images (good weather condition)

The point clouds shown in figures 5 and 6 present the test area. The point cloud generated from images acquired in poor weather conditions has a lower points density. Particularly apparent gaps in coverage occur within the built-up and vegetated areas. Based on visual analysis and the statistical clouds values it can be noticed that the point cloud generating algorithms are sensitive to the quality of the used images. The algorithms find a point for every pixel on the image. In the case of the point cloud generated from images acquired in poor weather conditions, the altitudes of points assigned to objects located above the terrain level are often incorrectly estimated. This phenomenon in not observable in the case of point clouds generated from images acquired in good weather conditions. This leads the automatic DSM and DTM filtering to be encumbered with errors. On the point cloud generated from image data acquired in poor weather conditions the pavement surfaces are visibly rougher than they should be, which shows that there are small errors which should be eliminated in the post-processing.

Absolute accuracy of the generated point clouds is evaluated using the independent check points. All points were signalised and measured using GNSS RTK technique.

The independent check points were identified on coloured point clouds based on the knowledge of their approximate coordinates. The independent check points were located on the flat surfaces.

\begin{tabular}{|c|c|c|c|}
\hline & & $\begin{array}{l}\text { Point Cloud I } \\
\text { (poor weather } \\
\text { conditions) }\end{array}$ & $\begin{array}{l}\text { Point Cloud II } \\
\text { (good weather } \\
\text { conditions) }\end{array}$ \\
\hline \multicolumn{2}{|c|}{$\begin{array}{c}\text { Number of } \\
\text { independent check } \\
\text { points }\end{array}$} & \multicolumn{2}{|c|}{21} \\
\hline \multirow{4}{*}{$\begin{array}{c}\text { RMSE } \\
{[\mathrm{m}]}\end{array}$} & $X$ & 0.085 & 0.056 \\
\hline & Y & 0.066 & 0.045 \\
\hline & $\mathrm{Z}$ & 0.021 & 0.027 \\
\hline & 3D & 0.11 & 0.08 \\
\hline
\end{tabular}

Table 4. Point clouds absolute accuracy
Given that the values presented in Table 4 are encumbered with identification errors and the density of point clouds, it can be observed that the point cloud generated in good weather conditions is characterised by a higher absolute point location accuracy. Based on analysis of the computed error values it can be noted that in both cases, the smallest error values were obtained for $\mathrm{Z}$ coordinates. They were equal to 0.021 and $0.027 \mathrm{~m}$ respectively. The results demonstrate a high vertical coordinates' accuracy in the generated point cloud. This is also related to the fact that independent check points were located on flat surfaces.

Additional point cloud comparative analysis were performed in CloudCompare software (Girardeau-Montaut, 2014), which was used to determine the distance between related points in the point clouds. The analysis were referred to the entire data set. The point cloud generated from images acquired in poor weather conditions was adopted as the reference data.

\begin{tabular}{|c|c|c|}
\hline \multicolumn{3}{|c|}{ Cloud comparison } \\
\hline \multirow{2}{*}{$\begin{array}{c}\text { nd } \\
1^{\text {st }} \text { Point Cloud to }\end{array}$} & $\begin{array}{c}\text { 3D Mean Distance } \\
{[\mathrm{m}]}\end{array}$ & 0.091 \\
\cline { 2 - 3 } & $\begin{array}{c}\text { Standard deviation } \\
{[\mathrm{m}]}\end{array}$ & 0.047 \\
\hline
\end{tabular}

Table 5. Cloud comparison distance and standard deviation for the tested Point Clouds

Based on a comparative analysis of the two point clouds (Table 5), it can be noticed that the average distance between the coordinates of the compared points are as high as $1.5 \mathrm{GSD}$ $(0.09 \mathrm{~m})$, while the standard deviation for all the variances equals to $0.047 \mathrm{~m}$. Therefore it can be concluded that the generated point clouds were only slightly shifted apart. This could be caused by a lower density of point cloud generated from images acquired in poor weather conditions as well as by lower accuracy of the block adjustment, from which the cloud was generated

\section{DIGITAL TERRAIN MODEL EXTRACTION}

Based on the comparative analysis it can be observed that the point clouds are characterised by a high noise ratio, compared to their relatively high density. This is due to the fact that the quality of point clouds is strongly dependant on the quality of the image data. In case of generating point clouds from images acquired in poor weather conditions the point clouds are more sparse and noisy, compared to using images captured in good weather conditions. Therefore, a key aspect of generating terrain models is selecting appropriate correlation parameters, depending on the quality and type of image data, as well as the further filtering and cloud points' classification. The largest problems with the elimination of Digital Surface Model points occur within woodlands and heavily urbanized areas (Figure 7). 


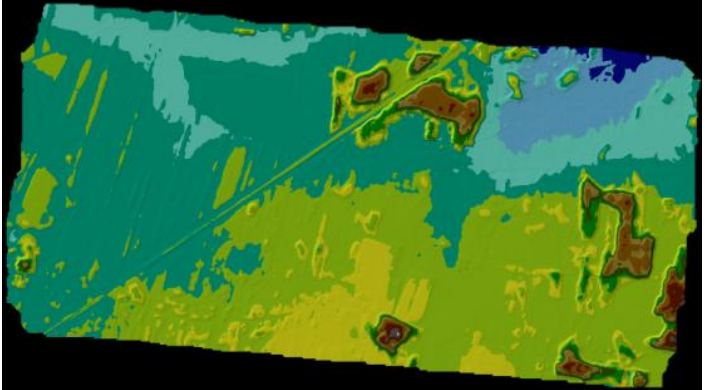

Figure 7. DSM obtained from the first data set (poor weather conditions)

The main problem with filtrating vegetation areas is to design a method of distinguishing points representing vegetation surfaces from the terrain surface. The surface interpolated based on generated points includes occasionally tree tops, some terrains above the ground level (green vegetation, low shrubs) and the ground level. Based on the point clouds Digital Surface Models with resolution of $20 \mathrm{x}$ GSD $(1.2 \mathrm{~m})$ were generated. These models were subject to a manual filtration in order to create a Digital Terrain Models. The generated models' accuracy analysis were conducted based measuring the altitudes on the independent check points. The standard deviations of the DTM points were equal to $0.092 \mathrm{~m}$ and $0.068 \mathrm{~m}$ for the first and the second data set respectively. The results demonstrate higher accuracy for the DTM generated from images acquired in good weather conditions.

\section{ORTHORECTIFICATION AND MOSAICING}

Generating orthophotomap from images obtained at low altitudes in its initial stage is no different from the traditional aerial photographs' processing method. However, due to the relatively low threshold of acquiring image data, equal to about $200 \mathrm{~m}$ and the use of non-metric camera, which results in lower quality images (radiometric quality, image blur, the lens brightness), it is necessary to set the forward and side overlap coverage at $75 \%$.

In most programs orthorectification process is fully automated. The areas or expected orthophotos are generated by default, however it is possible to set them manually. The basic parameters to be defined for orthorectification include: the final orthoimage pixel size, the output file format (most commonly * .tiff format) and an input file that allows to generate an orthomosaic from the selected images. The need to stack othophotos, or to perform mosaicking process occurs when a single sheet of ortophotomap contains more than one orthophoto. The above applies in nearly all of the low altitude image acquiring projects. The mosaicking is based on merging single ortophotos into a bigger sheet, taking into account their tonal alignment. A digital otophotomap is obtained as the result of this operation. The mosaicking process is divided into two stages: combining the orthophotos and correcting their radiometry. At the first step, the mosaicking line and the tonal alignment parameters for this line are determined. Secondly, radiometric parameters of the merged images are being adjusted.

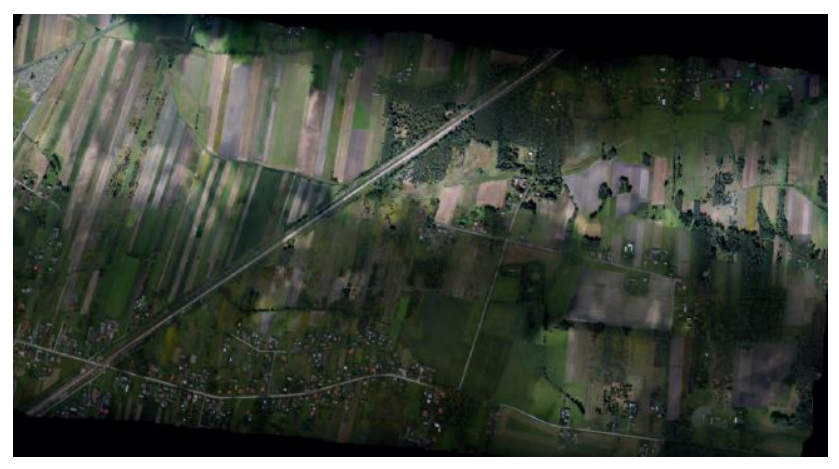

Figure 8. Orthomosaic from poor quality images

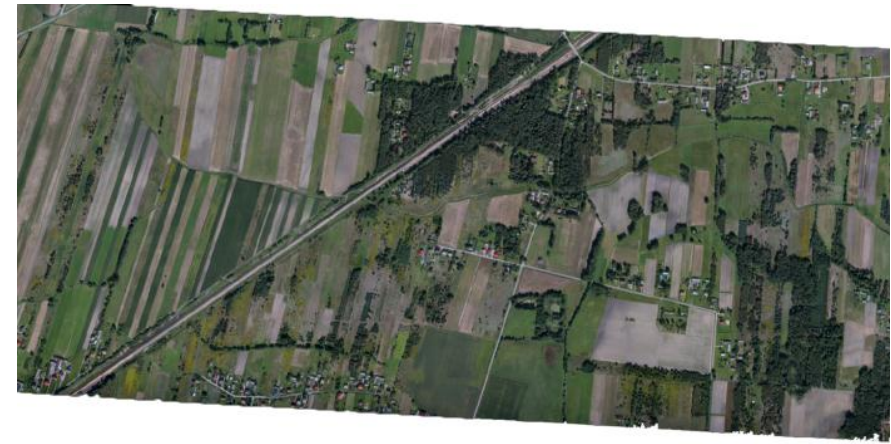

Figure 9. Orthomosaic from good quality images

Based on the results of conducted orthorectification and automatic mosaicking of two image blocks obtained in a different weather conditions (figures 8 and 9) it can be observed that the images acquired in poor weather conditions are not suitable for creating an ortophotomap of a satisfactory radiometric quality. The radiometric correction of images acquired from low altitudes is necessary because of lens brightness decease, lens vignetting, a sudden change of lighting conditions and exposure errors. Although in most cases the mosaicking process is automated, not always this solution allows to obtain a radiometrically correct orthomosaic. Both in automatic and manual mosaicking process it was not possible to align the images tonally. Moreover, on the automatically generated mosaics pixel shift errors were observed. The figure 9 presents mosaicking errors for images acquired in poor weather conditions.

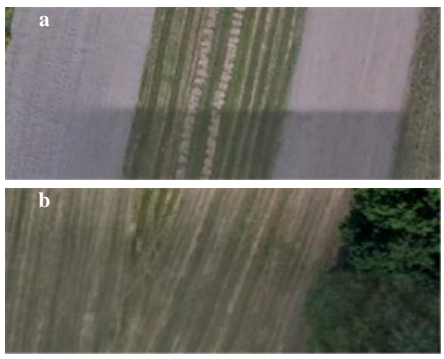

Figure 9. Example radiometric imperfections of automatic mosaicking process

During mosaicking orthophotos generated from low altitude image data, an extra care should be paid to woodland terrains. Some areas are captured on a far larger number of photos (tens or even hundreds) than in case of conventional photogrammetric projects where large format cameras are used (usually a few pictures). Hereby these areas frequently cover the 
entire image. This not only causes difficulties in generating of tie points (early processing stages), but also it primarily affects the mosaicking quality. The orthomosaic errors are the greatest and the most visible is the areas covered by dense vegetation.

\section{DISCUSSION AND CONCLUSION}

This paper presents the results of experiments and analysis of aerial triangulation, quality of point clouds generated from images acquired in various weather conditions from low altitudes, as well as of generating Digital Terrain Models, orthorectification and mosaicking. It has been shown that the weather conditions decrease the radiometric quality of images. Lower quality directly affects the bundle adjustment results together with accuracy and density of generated point clouds and digital terrain model. The above mentioned factors consequently worsen the accuracy of orthophotomap. The obtained results comprise to a valuable source of information regarding accuracies of adjustments of images acquired in poor weather conditions. In the forthcoming research we would like to focus on increasing the accuracy of low quality images processing. In specific cases when the raid must be performed during overcast or rain, in order to obtain satisfying accuracy of the processing, the flight parameters should be adequately customised. The authors believe that while acquiring images in poor weather conditions, in order to obtain results comparably accurate as in case of using photos taken in good conditions the requested GSD should be reduced by $25-30 \%$. In consequence, for most systems this will result in reduction of the flight altitude. However it should be remarked that reducing the flight's height increases the number of images and raids required to cover the given photographed area.

\section{ACKNOWLEDGEMENTS}

This paper is part of research work carried out in the project PBS/854/2013 financed by Military University of Technology, the Faculty of Civil Engineering and Geodesy, Poland.

\section{REFERENCES}

Cavegn, S., Haala, N., Nebiker, S., Rothermel, M., \& Tutzauer, P. 2014. Benchmarking high density image matching for oblique airborne imagery. ISPRS-International Archives of the Photogrammetry, Remote Sensing and Spatial Information Sciences, 1, 45-52.

H. Chao, C. Coopmans, L. Di, Y. Chen, 2010 . A comparative evaluation of low-cost IMUs for unmanned autonomous systems, In Multisensor Fusion and Integration for Intelligent Systems (MFI), 2010 IEEE Conference, 211-216.

Förstner, W., Gülch E. 1987. A Fast Operator for Detection and Precise Location of Distinct Points, Corners and Centers of Circular Features. In: Proceedings of the ISPRS Intercommission Workshop on Fast Processing of Photogrammetric Data., pp. 281- 305.

Förstner, W. 1995. Matching strategies for point transfer. In Photogrammetric Week '95; Fritch, D., Hobbie, D., Eds.; Wichmann Verlag: Heidelberg, Germany, pp. 173-183.

Gerke, M., 2009. Dense Matching in High Resolution Oblique Airborne Images. In: U. Stilla, F. Rottensteiner \& $N$. Paparoditis (Eds.), CMRT09, Int. Arch. Photogramm. Remote
Sens. Spatial Inf. Sci., Paris, France, Vol. XXXVIII, Part 3/W4, pp. 77-82.

Girardeau-Montaut, D., 2015. CloudCompare - Open Source Project. http://www.danielgm.net/cc/ (accessed 25 january 2015).

Gülch, E. 2009. Advaced matching techniques for high precision surface and terrain models. In

Photogrammetric Week '09; Fritch, D., Ed.; Wichmann Verlag: Heidelberg, Germany, pp. 303-315.

Grün, A. 1985. Adaptive least squares correlations: a powerful matching techniques. South African J. Photogramm. Remote Sensing and Cartography, 14(3), pp. 175-187.

Haala N. 2011. Multiray Photogrammetry and Dense Image Matching, Photogrammetric Week 2011, Wichmann Verlag, Berlin/Offenbach ,Germany, pp. 185-195.

Haala, N., 2014. Dense Image Matching Final Report. EuroSDR Publication Series, Official Publication No. 64, pp.115-145.

Haala, N. 2009. Comeback of digital image matching. In Photogrammetric Week '09; Fritch, D., Ed.;

Wichmann Verlag: Heidelberg, Germany, pp. 289-301.

Haala, N.; Hastedt, H.; Wolf, K.; Ressl, C.; Baltrusch, 2010. S. Digital photogrammetric cameraevaluation-Generation of digital elevation models. Photogramm. Fernerkund. Geoinf., 2, 99-115.

Hardin, P.J., and Jensen, R.R. 2011. Small-scale unmanned aerial vehicles in environmental remote sensing: challenges and opportunities. GIScience \& Remote Sensing. 48(1): 99-111

Hernandez-Lopez, D., Felipe-Garcia, B., Gonzalez-Aguilera, D., \& Arias-Perez, B., 2013. An Automatic Approach to UAV Flight Planning and Control for Photogrammetric Applications. Photogrammetric Engineering \& Remote Sensing, 79(1), 87-98.

Hirschmüller H., 2011. Semi Global Matching Motivation, Developments and Applications. Photogrammetric Week (53) ,pp. 173-181.

Hirschmüller H., 2005. Accurate and efficient stereo processing by semi-global matching and mutual information. Proceedings of the IEEE Computer Society Conference on Computer Vision and Pattern Recognition (CVPR). Tom 2. San Diego, CA, USA, pp. 807-814.

Lowe, D. 2004 Distinctive Image Features from Scale-Invariant Keypoints. International Journal of Computer Vision. Vol. 60, No. 2, pp. 91-110.

Kędzierski, M. , Wierzbicki, D., Wilińska, M.., Fryśkowska, A.. 2013. Analiza możliwości wykonania aerotriangulacji zdjęć cyfrowych pozyskanych kamerą niemetryczną zamontowaną na pokładzie bezzałogowego statku latającego bez systemu GPS/INS. Biuletyn Wojskowej Akademii Technicznej, 62(4), pp. 241-251, (In Polish)

Mancini, F., Dubbini, M., Gattelli, M., Stecchi, F., Fabbri, S., \& Gabbianelli, G. 2013. Using Unmanned Aerial Vehicles (UAV) for High-Resolution Reconstruction of Topography: The 
Structure from Motion Approach on Coastal Environments. Remote Sensing, 5(12), 6880-6898.

Schenk, T. 1999. Digital Photogrammetry. TerraScience, Laurelville, $\mathrm{OH} 43135,428$ pages.

Rupnik, E., Nex, F. \& Remondino, F. 2014. Oblique MultiCamera Systems - Orientation and Dense Matching Issues. In: Int. Arch. Photogramm. Remote Sens. Spatial Inf. Sci.,Castelldefels, Spain, Vol. XL-3, Part W1, pp. 107-114.

Rothermel M. \& Haala N. 2011. Potential of Dense Matching for the Generation of High Quality Digital Elevation Models, ISPRS Hannover Workshop 2011: High-Resolution Earth Imaging for Geospatial Information, IASPRS, Volume XXXVIII4/W19,Germany.

Rosnell, T., Honkavaara, E. 2012. Point cloud generation from aerial image data acquired by a quadrocopter type micro unmanned aerial vehicle and a digital still camera. Sensors, $12(1), 453-480$

Schenk, T. 1999. Digital Photogrammetry. TerraScience, Laurelville, $\mathrm{OH} 43135,428$ pages.

Westoby, M. J., Brasington, J., Glasser, N. F., Hambrey, M. J., \& Reynolds, J. M. 2012. 'Structure-fromMotion'photogrammetry: A low-cost, effective tool for geoscience applications. Geomorphology, 179, 300-314. 